\title{
The in vitro estrogenic activity of the crude drugs found in Japanese herbal medicines prescribed for menopausal syndrome was enhanced by combining them
}

\author{
Zeyun Wang, Seiji Kanda*, Takaki Shimono, Dambajamts Enkh-Undraa and Toshimasa Nishiyama
}

\begin{abstract}
Background: Japanese herbal medicines can be used as alternatives to estrogen therapy and are sometimes prescribed for menopausal syndrome because they have fewer side effects and are associated with better compliance than estrogen therapy, but little is known about the pharmacological mechanisms of such treatments. This study aimed to explore the mechanisms responsible for the estrogen-like effects of five widely prescribed Japanese herbal medicines (unkeito, kamishoyosan, nyoshinsan, keishibukuryogan, and tokishakuyakusan).

Methods: We evaluated the estrogenic activity of these five Japanese herbal medicines and their metabolites using an estrogen receptor (ER)-dependent cell proliferation bioassay and an ER-dependent reporter assay. We also investigated the estrogenic activity of the crude drugs within the medicines and attempted to detect intercrude drug synergistic effects using the ER-dependent reporter assay.

Results: We found that unkeito, kamishoyosan, and nyoshinsan exhibited estrogenic activity, and they displayed stronger estrogenic activity after being metabolized. Then, we focused on investigating the estrogenic activity of the crude drugs present within unkeito. We found that glycyrrhizae radix, cinnamomi cortex, evodiae fructus, and zingiberis rhizoma demonstrated ERß-dependent estrogenic activity. The combined use of evodiae fructus and glycyrrhizae radix, or evodiae fructus and cinnamomi cortex produced synergistic ERß-dependent estrogenic activity.

Conclusion: It was suggested that unkeito, kamishoyosan, and nyoshinsan exert estrogenic activity, and hence, might be useful for treating menopausal syndrome. Furthermore, synergistic estrogenic effects were detected between some of the crude drugs present within unkeito.
\end{abstract}

Keywords: Estrogenic activity, Japanese herbal medicines, Metabolism, Synergistic effect

\section{Background}

The menopause is a biological stage in a woman's life when her ovarian function diminishes and eventually ceases. It involves the cessation of both egg maturation and sex hormone (principally estrogen and progesterone) secretion. Many women experience menopausal syndrome, which can cause hot flushes, night sweats, menstrual irregularities, vaginal dryness, etc., during the menopause and perimenopause [1-3]. Estrogen therapy is widely used to treat menopausal syndrome. The biological

\footnotetext{
* Correspondence: kandas@hirakata.kmu.ac.jp

Department of Public Health, Kansai Medical University, 2-5-1, Shin-machi, Hirakata-shi, Osaka 573-1010, Japan
}

(c) The Author(s). 2018 Open Access This article is distributed under the terms of the Creative Commons Attribution 4.0 International License (http://creativecommons.org/licenses/by/4.0/), which permits unrestricted use, distribution, and reproduction in any medium, provided you give appropriate credit to the original author(s) and the source, provide a link to the Creative Commons license, and indicate if changes were made. The Creative Commons Public Domain Dedication waiver (http://creativecommons.org/publicdomain/zero/1.0/) applies to the data made available in this article, unless otherwise stated. receptors (ER); i.e., ER $\alpha$ and ER $\beta$, which are encoded by different genes and exhibit tissue-type- and cell-typespecific expression. The activation of each subtype leads to different effects. In addition, ER $\alpha$ is associated with certain types of estrogen-dependent tumors, such as breast [4], endometrial [5], and ovarian cancer [6]. On the other hand, it has been found that ER $\beta$ expression can inhibit motility and cell invasion in breast [7], prostate [8], and ovarian cancer cells [9]. For example, estrogen increased the proliferation of breast cancer cells in the presence of $E R \alpha$, but this was inhibited in the presence of $\operatorname{ER} \beta$ [10]. Therefore, while estrogen therapy might have rapid effects 
on menopausal syndrome, it might also increase the risk of estrogen-dependent tumors.

Herbal medicines are derived from various plants and have been prescribed to treat many diseases for thousands of years. It was previously reported that phytoestrogens, such as daidzein and daidzin, can be found in puerariae radix [11], and the glabridin present in licorice roots was suggested to be a useful treatment for postmenopausal women because of its estrogenic activity [12-14]. Herbal medicines have recently been used as an alternative to estrogen therapy for menopausal syndrome, but little is known about the pharmacological activity of such medicines. In this study, we evaluated the estrogenic activity of five widely used Japanese herbal medicines (unkeito [UKT], kamishoyosan [KSS], nyoshinsan [NSS], keishibukuryogan [KBG], and tokishakuyakusan [TSS]), in order to explain their pharmacological activity against menopausal symptoms.

We examined the estrogenic activity of these five Japanese herbal medicines using a combination of an ERdependent cell-MtT/Se cell proliferation bioassay and a yeast two-hybrid reporter assay. The MtT/Se cell line was established from rat pituitary cells [15], and both ER $\alpha$ and ER $\beta$ are expressed in the cytoplasm around the nuclei of these cells [16]. It was reported that this cell line responds well (and dose-dependently) to $17 \beta$-estradiol (E2) stimulation, and the E2-induced proliferation of $\mathrm{MtT} / \mathrm{Se}$ cells was dose-dependently inhibited by tamoxifen [15]; therefore, an assay based on $\mathrm{MtT} / \mathrm{Se}$ cell proliferation was developed to evaluate the estrogenic activity of test substances [16]. In addition, a yeast-based estrogen screening test based on the yeast two-hybrid system was used to clarify the estrogenic activity of Japanese herbal medicines. This system was constructed by inserting the ligand-binding domain (LBD) of the human estrogen receptor and its coactivator into yeast cells, which allowed the specific binding of ligands to the ER-LBD. Estrogenic activity was then quantitatively evaluated based on the expression level of a reporter gene encoding the $\beta$-galactosidase enzyme [17].

Like all drugs, the chemical structures and pharmacological activity of Japanese herbal medicines might be altered by the enzymatic systems found in living organisms. For example, the estrogenic activity of the phytoestrogenrich plant Pueraria mirifica has been found to increase significantly after being metabolized [18]. Therefore, the metabolic modulation of estrogenic activity must be considered in any assessment of the impact of Japanese herbal medicines. In this study, we also investigated the estrogenic activity of Japanese herbal medicines after they had been metabolized by the rat liver S9 fraction.

Herbal medicines are composed of a mixture of several crude drugs. In order to study the pharmacological activity of herbal medicines, we first need to confirm which of the crude drugs present within them are responsible for such activity. We assessed the estrogenic activity of the crude drugs using the same protocol as was used to study the Japanese herbal medicines. We also conducted an experiment to detect inter-crude drug synergistic effects.

\section{Methods \\ Medicines and extraction}

Japanese herbal medicines; i.e., UKT (unkei decoction, TJ-106), KSS (kamishoyo powder) (TJ-24), NSS (nyoshin powder, TJ-67), KBG (keishibukuryo pills, TJ-25), and TSS (tokishakuyaku powder, TJ-23), were obtained from Tsumura Corporation (Tokyo, Japan) in the form of dried powder extracts.

Each herbal medicine extract powder was manufactured as an aqueous extract containing processed raw materials in the ratios shown in Table 1 . The qualities of these raw materials were tested as set out in the Japanese Pharmacopoeia. Each herbal medicine was extracted with purified water at $95^{\circ} \mathrm{C}$ for $1 \mathrm{~h}$. The extract solution was separated from the non-soluble waste and concentrated by removing water under reduced pressure. Spray-drying was used to produce a dried extract powder. The same extraction procedure was applied to each crude drug.

The active ingredient of each powdered medicine was extracted by mixing $1 \mathrm{~g}$ of powder with $10 \mathrm{ml}$ of $99.5 \%$ ethanol and rotating the mixture for $4 \mathrm{~h}$ in our laboratory. The mixture was then filtered through a $0.45-\mu \mathrm{m}$ filter membrane. The solvent was evaporated to dryness at room temperature in a vacuum, and the residue was dissolved in dimethyl sulfoxide (DMSO) (Wako Chemical, Japan). The concentration of each extract was adjusted with DMSO as required for each assay.

\section{Metabolic activation}

In this study, in vitro metabolic activation via the addition of the rat liver S9 fraction (Sigma Aldrich, Saint Louis, USA) was used to metabolize the examined Japanese herbal medicines. Metabolic activation was induced using an S9 mixture containing $0.5 \mathrm{mg} / \mathrm{ml}$ of the $\mathrm{S} 9$ fraction in $100 \mathrm{mM}$ potassium phosphate buffer (pH 7.4), $3.3 \mathrm{mM} \mathrm{MgCl} 2$ (Wako Chemical, Japan), and an NADPH-generating system [1.3 mM NADP (Sigma Aldrich, USA), $3.3 \mathrm{mM}$ glucose 6-phosphate (Oriental Yeast, Tokyo, Japan), and 0.4 units/ml of glucose-6phosate dehydrogenase (Oriental Yeast, Tokyo, Japan)]. Each 200- $\mu$ l sample of Japanese herbal medicine dissolved in DMSO was incubated with $800 \mu \mathrm{l}$ of the S9 mixture at $37^{\circ} \mathrm{C}$ for $1 \mathrm{~h}$ or with $800 \mu \mathrm{l}$ of the negative mixture, which was composed of the abovementioned S9 mixture minus the S9 fraction, as a negative control. The metabolized Japanese herbal medicines were stored at $-80^{\circ} \mathrm{C}$ until use. 
Table 1 The mass ratio of crude drugs in the Japanese herbal medicines

\begin{tabular}{|c|c|c|c|c|c|c|}
\hline herbal & $\begin{array}{l}\text { simplified } \\
\text { form }\end{array}$ & $\begin{array}{l}\text { Kamishoyosan } \\
\text { KSS }\end{array}$ & $\begin{array}{l}\text { Keishibukuryogan } \\
\text { KBG }\end{array}$ & $\begin{array}{l}\text { Nyoshinsan } \\
\text { NSS }\end{array}$ & $\begin{array}{l}\text { Tokishakuyakusan } \\
\text { TSS }\end{array}$ & $\begin{array}{l}\text { Unkeito } \\
\text { UKT }\end{array}$ \\
\hline alismatis rhizoma & ar & & & & 4 & \\
\hline angelicae acutilobae radix & aar & 3 & & 3 & 3 & 3 \\
\hline arecae semen & as & & & 2 & & \\
\hline asini corii collas & acc & & & & & 2 \\
\hline atractylodis lanceae rhizoma & alr & 3 & & 3 & 4 & \\
\hline bupleuri radix & $\mathrm{br}$ & 3 & & & & \\
\hline caryophylli flos & cf & & & 1 & & \\
\hline cinnamomi cortex & $\mathrm{CC}$ & & 3 & 2 & & 2 \\
\hline cnidii rhizoma & $\mathrm{cr}$ & & & 3 & 3 & 2 \\
\hline coptidis rhizoma & $\mathrm{ctr}$ & & & 1 & & \\
\hline cyperi rhizoma & cer & & & 3 & & \\
\hline evodiae fructus & ef & & & & & 1 \\
\hline gardeniae fructus & gf & 2 & & & & \\
\hline ginseng radix & gra & & & 2 & & 2 \\
\hline glycyrrhizae radix & gr & 1.5 & & 1 & & 2 \\
\hline menthae herba & $\mathrm{mh}$ & 1 & & & & \\
\hline moutan cortex & $\mathrm{mc}$ & 2 & 3 & & & 2 \\
\hline ophiopogonis radix & or & & & & & 4 \\
\hline paeoniae radix & pr & 3 & 3 & & 4 & 2 \\
\hline persicae semen & ps & & 3 & & & \\
\hline pinelliae tuber & $\mathrm{pt}$ & & & & & 4 \\
\hline poria sclerotium & pst & 3 & 3 & & 4 & \\
\hline saussureae radix & sr & & & 1 & & \\
\hline scutellariae radix & $\mathrm{scr}$ & & & 2 & & \\
\hline zingiberis rhizoma & $\mathrm{zr}$ & 1 & & & & 1 \\
\hline
\end{tabular}

The mass ratio of crude drugs in the Japanese herbal medicines was provided to us by Tsumura Corporation. In order to simplify the name of herbal medicines and crude drugs in text, we made the simplified forms in the table

\section{Cell culture and maintenance of the MtT/se cells}

Rat mammotropic pituitary tumor cells, MtT/Se cells, were donated by the Riken Bioresource Center cell bank in Japan. The MtT/Se cells were routinely cultured in Dulbecco's modified Eagle's medium (DMEM)/HamF12 (1:1) medium (Nacalai Tesque, Japan) containing 2.5\% fetal bovine serum (FBS) (HyClone, USA), 10\% horse serum (HS) (Invitrogen, USA), and $1 \times 10^{-9} \mathrm{M}$ of estradiol (E2) (Wako Chemical, Japan). The cells were incubated at $37^{\circ} \mathrm{C}$ in a humidified atmosphere of $5 \% \mathrm{CO}_{2}$ and $95 \%$ air.

\section{ER-dependent cell proliferation bioassay}

Before the cell proliferation bioassay, the MtT/Se cells were maintained for 4 days in routine medium from which E2 had been removed, as described above. In the proliferation assay, the MtT/Se cells were placed in phenol red-free DMEM/HamF12 (1:1) medium (Nacalai Tesque, Japan) containing 2.5\% charcoal dextran-treated FBS (HyClone,
USA) and $10 \% \mathrm{HS}$ at a density of $1 \times 10^{5}$ cells $/ \mathrm{ml}$, before being seeded at $95 \mu \mathrm{l} /$ well in 96-well microplates. Then, the cells in each well were incubated with $5 \mu \mathrm{l}$ of each test substance for 6 days. In order to clarify whether the herbal medicines induced cell proliferation through ER-mediated mechanisms or other general mitogenic pathways, ICI182,780, an ER antagonist (Abcam, UK), was added as a competitor. Cells that were incubated with DMSO alone were used as a control, and the final concentration of DMSO in all wells was $0.1 \%$. Six days later, cell proliferation was measured with a modified MTT assay based on WST-8, a highly water-soluble tetrazolium salt (Dojindo, Japan). The amount of formazan dye formed by metabolically active cells was quantified by measuring the absorbance of each well at $450 \mathrm{~nm}$. The estrogenic activity of each test substance was evaluated based on the cell proliferation that occurred in its presence, which was calculated by comparing the associated $A_{450 n m}$ value with the $A_{450 n m}$ value of the control, DMSO. 
Cell proliferation $(\%)=\left(\mathrm{A}_{450 \mathrm{~nm} \text { test }} / \mathrm{A}_{450 \mathrm{~nm} \text { DMSO }}\right) \times 100 \%$.

\section{ER-dependent reporter assay (yeast two-hybrid assay)}

In this study, we used human ER $\alpha(h E R \alpha)$ and $h E R \beta$ yeast cells carrying the LBD of hER $\alpha$ or $h E R \beta$ and the coactivator transcriptional intermediary factor 2 (TIF2) (the cells had been transfected with two expression plasmids, pGBT9-ERLBD and pGAD424-TIF2) [19].

The yeast cells were pre-incubated and shaken overnight at $30^{\circ} \mathrm{C}$ in selective medium (SD medium lacking tryptophan and leucine). A 100- $\mu \mathrm{l}$ sample of the overnight yeast cell culture was added to $400 \mu \mathrm{l}$ of fresh medium containing $5 \mu \mathrm{l}$ of one of the test substances. After being incubated for $4 \mathrm{~h}$ at $30^{\circ} \mathrm{C}$, the yeast cells were collected by centrifugation and resuspended in $250 \mu \mathrm{l} \mathrm{Z}$-buffer [0.1 M sodium phosphate (Wako Chemical, Japan), $10 \mathrm{mM} \mathrm{KCl}$ (Wako Chemical, Japan), $1 \mathrm{mM} \mathrm{MgSO} 4$ (Wako Chemical, Japan)]. Then, $150 \mu \mathrm{l}$ of the cell suspension were added to a 96-well microplate, and the cell density of each well was measured based on its $A_{600 n m}$ value. Next, the cell walls of the remaining $100 \mu \mathrm{l}$ of yeast cells were digested enzymatically by incubating them with $100 \mu \mathrm{l}$ of $2 \mathrm{mg} / \mathrm{ml} \mathrm{Zymo-}$ lyase $20 \mathrm{~T}$ (Nacalai Tesque, Japan) at $37^{\circ} \mathrm{C}$ for $30 \mathrm{~min}$. Then, the $200-\mu \mathrm{l}$ lysate was mixed with $40 \mu \mathrm{l} \mathrm{of} 4 \mathrm{mg} / \mathrm{ml}$ o-nitrophenyl- $\beta$ - $D$-galactopyranoside (ONPG) (Sigma Aldrich, USA) and incubated at $30^{\circ} \mathrm{C}$ for $1 \mathrm{~h}$, before the enzymatic reaction was stopped by the addition of $100 \mu \mathrm{l}$ of $1 \mathrm{M} \mathrm{Na}_{2} \mathrm{CO}_{3}$ (Wako Chemical, Japan). Then, the yeast debris was removed by centrifugation, and the absorbance of the supernatant was measured at $450 \mathrm{~nm}$. $\beta$ galactosidase activity was calculated using the following equation:

\section{$\beta$-galactosidaseactivity (units)}

$$
=1000 \times \mathrm{A}_{450 \mathrm{~nm}} /\left(60 \min \times 0.1 \mathrm{ml} \times \mathrm{A}_{600 \mathrm{~nm}}\right)
$$

, where $A_{600 n m}$ represents the cell density at the start of the assay, $\mathrm{A}_{450 \mathrm{~nm}}$ represents the absorbance of the supernatant at the end of enzymatic reaction, $60 \mathrm{~min}$ is the duration of the enzymatic reaction, and $0.1 \mathrm{ml}$ is the volume of the yeast cell culture used in the enzymatic reaction.

The ER $\alpha$ estrogenic activity of the tested Japanese herbal medicines was evaluated based on the $\beta$-galactosidase activity of hER $\alpha$ yeast cells, and their ER $\beta$-dependent estrogenic activity was assessed based on the $\beta$-galactosidase activity of hER $\beta$ yeast cells. $\mathrm{REC}_{10}$ (the concentration that produced an activity level equivalent to $10 \%$ of the maximum activity of E2) was used to evaluate the estrogenic activity of the Japanese herbal medicines.

\section{Combination study of synergism and synergy quotient calculations}

As shown in Table 1, Japanese herbal medicines are composed of various crude drugs, and we tried to identify pairs of crude drugs that had synergistic effects. In the combinatorial study, each pair of crude drugs was added to yeast cells in a 1:1 ratio. The combinatorial study was performed to detect synergistic crude drug effects on ER $\beta$-dependent estrogenic activity compared with the activity seen during the administration of each drug alone.

The synergism quotient (SQ) was calculated by subtracting the baseline values (the $\beta$-galactosidase activity values of DMSO) from all treatments and then dividing the activity value of the combined treatment by the sum of the activity values for the individual treatments. A SQ of $>1.0$ indicated a synergistic effect $[20,21]$.

\section{D-high-performance liquid chromatography (HPLC) analysis}

In this study, 3D-HPLC analyses of the herbal medicines were performed by Tsumura Corporation to identify each of their components.

The HPLC apparatus consisted of a Shimadzu LC-10A (analysis software: CLASS-M10A ver. 1.64, Tokyo, Japan) equipped with a multiple wavelength detector (wavelength range: $200-400 \mathrm{~nm}$; Shimadzu SPD-M10AVP diode array detector) and an autoinjector (Shimadzu CTO-10 AC). The HPLC conditions were as follows: column, TSK-GEL 80TS octadecylsilyl column (internal diameter: $250 \times$ $4.6 \mathrm{~mm}$; TOSOH, Tokyo, Japan); eluent, (A) $0.05 \mathrm{M}$ $\mathrm{AcONH}_{4}$ (pH 3.6), (B) $100 \% \mathrm{CH}_{3} \mathrm{CN}$. A linear gradient of $90 \% \mathrm{~A}$ and $10 \% \mathrm{~B}$ changing over $60 \mathrm{~min}$ to $0 \% \mathrm{~A}$ and $100 \%$ B was used. Once a B concentration of $100 \%$ had been achieved, it was maintained for $20 \mathrm{~min}$ (temperature, $40^{\circ} \mathrm{C}$; flow rate, $1.0 \mathrm{~mL} / \mathrm{min}$ ).

\section{Statistical analysis}

All experiments were conducted at least three times for each sample, and all data shown represent the mean \pm standard deviation (SD). The Kolmogorov-Smirnov test was used to confirm that all of the data for each sample exhibited a normal distribution. All statistical analyses were carried out using the Student's t-test in SPSS, version 15.0. $P$-values of $<0.05$ were considered to be statistically significant.

\section{Results}

The estrogenic activity of Japanese herbal medicines and their metabolites in an ER-dependent cell proliferation bioassay.

The estrogenic activity of each Japanese herbal medicine was evaluated using an MtT/Se cell proliferation assay. The cell proliferation that was induced by E2 plateaued at $10^{-7} \mathrm{M}$, and the mean cell proliferation activity level was 322\% higher than the activity induced by DMSO. UKT, KSS, and NSS induced significantly increased cell proliferation at final concentrations of $50 \mu \mathrm{g} / \mathrm{ml}$ and $100 \mu \mathrm{g} / \mathrm{ml}$. However, neither TSS nor KBG 
induced significant increases in cell proliferation at concentrations of $50 \mu \mathrm{g} / \mathrm{ml}$ or $100 \mu \mathrm{g} / \mathrm{ml}$ (Fig. 1a). When the cells were treated with $10 \mathrm{nM}$ of ICI, the proliferation induced by UKT, KSS, NSS, and E2 was inhibited (Fig. 1b). These results showed that UKT, KSS, and NSS induced
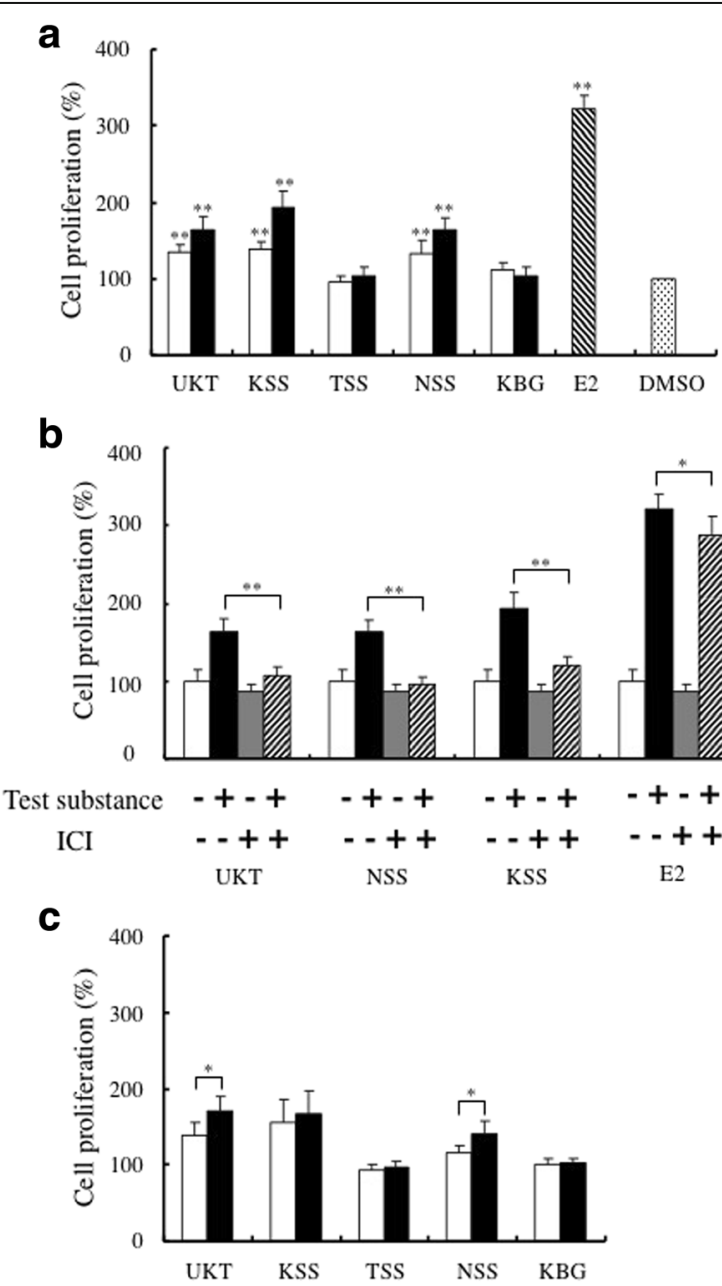

Fig. 1 The cell proliferation activity induced by Japanese herbal medicines. a MtT/Se cells were incubated with $50 \mu \mathrm{g} / \mathrm{ml}$ (white columns) or $100 \mu \mathrm{g} / \mathrm{ml}$ of each Japanese herbal medicine (black columns) or $10^{-7} \mathrm{M}$ of E2 for 6 days. Cell proliferative activity is shown as a percentage compared with that induced by DMSO alone in the MTT assay. ${ }^{*}$ significantly increased compared with the activity induced by DMSO, $p<0.01$. b Cells were treated with $10 \mathrm{nM}$ $\mathrm{ICl}$ alone or a combination of $10 \mathrm{nM} \mathrm{ICl}$ and $100 \mu \mathrm{g} / \mathrm{ml}$ of UKT, KSS, or NSS or $10^{-7}$ M E2 for 6 days. White columns: ICI(-)test substance(-); blank columns: $\mathrm{ICI}(-)$ test substance(+); gray columns: $\mathrm{ICI}(+)$ test substance(-); diagonal columns: ICI(+)test substance(+). ${ }^{* *}$ significantly inhibited the induction of cell proliferation compared with herbal medicines or $\mathrm{E} 2$ alone, $p<0.01 ;{ }^{*} p<0.05$. $\mathbf{c}$ The cell proliferation induced by metabolized Japanese herbal medicines. The Japanese herbal medicines were treated with the rat $\mathrm{S} 9$ fraction, and the proliferative activity induced by each Japanese herbal medicine ( $100 \mu \mathrm{g} / \mathrm{ml}$, black columns) was compared with that induced by the unmetabolized medicine (white columns). *significantly increased compared with the activity of the unmetabolized medicine, $p<0.05$ proliferation through ER-mediated mechanisms and not via other general mitogenic pathways. Thus, these three herbal medicines displayed estrogenic activity, and KSS exhibited the strongest activity in this bioassay.

In order to study the effects of the examined Japanese herbal medicines after they had been metabolized, we evaluated their estrogenic activity after they had been pre-treated with rat liver S9 extract in vitro. Metabolized $U K T$ and NSS induced significantly greater cell proliferation than unmetabolized UKT/NSS at a final concentration of $100 \mu \mathrm{g} / \mathrm{ml}$ (Fig. 1c). The estrogenic activity of KSS also increased after it was treated with $\mathrm{S} 9$, but the difference was not significant. These results showed that the estrogenic activity of $U K T$ and NSS increased about 1.2-fold after they were treated with S9. TSS and KBG did not show any estrogenic activity before or after they were metabolized.

Estrogenic activity of Japanese herbal medicines and their metabolites in a yeast two-hybrid assay.

Next, we evaluated the ER $\beta$-dependent estrogenic activity of the five examined Japanese herbal medicines. We analyzed the ER $\beta$-dependent estrogenic activity of each medicine using a reporter gene-based yeast twohybrid assay at final concentrations of $0.1 \mathrm{mg} / \mathrm{ml}$ to $10 \mathrm{mg} / \mathrm{ml}$ (Fig. 2a). Marked $\beta$-galactosidase activity was induced by UKT, KSS, and NSS, and the activity increased dose-dependently. These results suggested that UKT, KSS, and NSS exhibited estrogenic activity, which agrees with their estrogenic effects in the MtT/Se cell proliferation assay. On the other hand, TSS and KBG demonstrated low ER $\beta$-dependent estrogenic activity, even at higher concentrations. In addition, E2 induced ER $\beta$-dependent estrogenic activity at concentrations ranging from $1 \times 10^{-4} \mathrm{M}$ to $1 \times 10^{-11} \mathrm{M}$, and this activity plateaued at an E2 concentration of $1 \times 10^{-6} \mathrm{M}$. The REC $_{10}$ values of $U K T, K S S$, and NSS were $0.7 \mathrm{mg} / \mathrm{ml}$, $2.2 \mathrm{mg} / \mathrm{ml}$, and $4.5 \mathrm{mg} / \mathrm{ml}$, respectively. These results suggested that UKT, KSS, and NSS induced marked ER $\beta$-dependent estrogenic activity. UKT had the lowest $\mathrm{REC}_{10}$ value of the five examined Japanese herbal medicines, which showed that it produced the strongest ER $\beta$ dependent estrogenic activity. On the other hand, none of the five examined Japanese herbal medicines displayed $E R \alpha$ estrogenic activity in the yeast two-hybrid assay (data not shown).

The three herbal medicines that showed estrogenic activity in the yeast two-hybrid assay had their estrogenic activity assessed after being metabolized. The herbal medicines were pre-treated with a rat liver S9 mixture that included metabolic enzymes, and their estrogenic activity was compared with the estrogenic activity of the unmetabolized herbal medicines using the yeast twohybrid assay. The activity levels of the metabolized products are shown in Fig. 2b. The three herbal medicines 

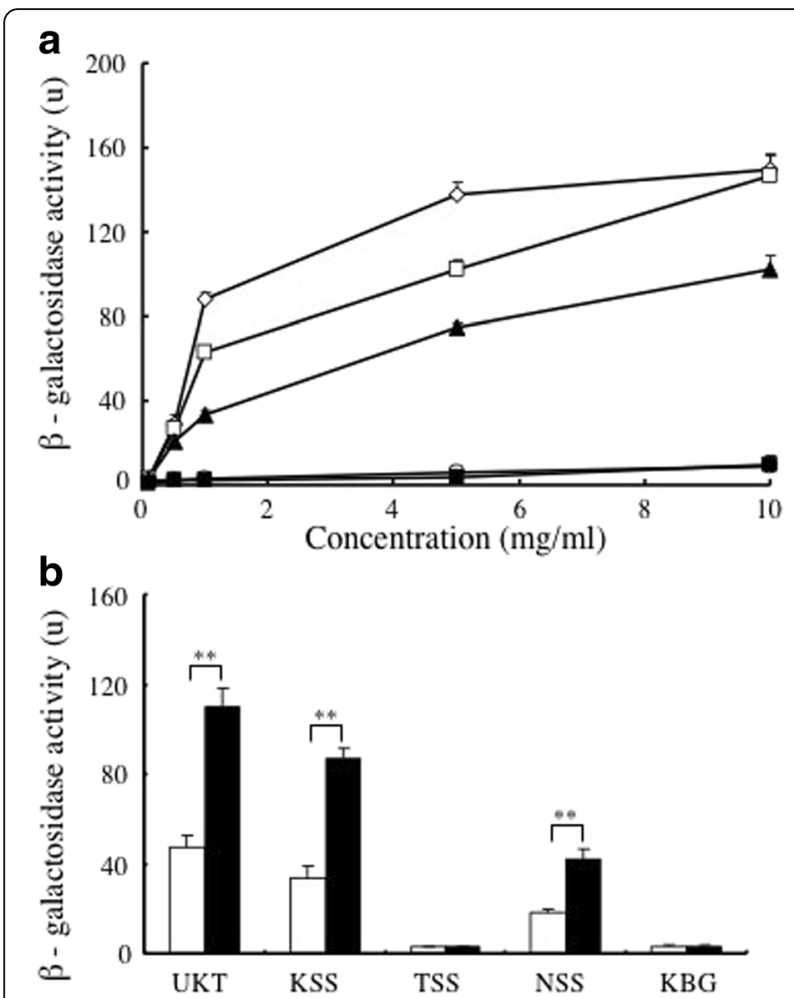

Fig. 2 The ERß-dependent estrogenic activity of the Japanese herbal medicines and the metabolized herbal medicines in the yeast twohybrid assay. a Yeast cells that had been transfected with hER $\beta$ were incubated with $0.1 \mathrm{mg} / \mathrm{ml}$ to $10 \mathrm{mg} / \mathrm{ml}$ of UKT ( $)$ ), KSS (口), TSS (O), NSS $(\boldsymbol{\Delta})$, or $K B G(\mathbf{-})$ for $4 \mathrm{~h}$ at $30^{\circ} \mathrm{C}$. ERß-dependent estrogenic activity was evaluated based on the $\beta$-galactosidase activity measured at $450 \mathrm{~nm}$ using ONPG as a substrate. $\mathbf{b}$ The Japanese herbal medicines $(1 \mathrm{mg} / \mathrm{ml})$ were treated with the rat $S 9$ fraction, and the ERß-dependent estrogenic activity of the metabolized herbal medicines (black columns) was compared with that of the unmetabolized medicines (white columns) using the yeast two-hybrid assay. ${ }^{* *}$ significantly increased compared with the activity of the unmetabolized medicine, $p<0.01$

that exhibited estrogenic activity in the yeast two-hybrid assay also showed significantly elevated ER $\beta$-dependent estrogenic activity after being treated with the rat liver S9 fraction. These results showed that metabolizing UKT, KSS, and NSS with the rat liver S9 fraction increased their ER $\beta$-dependent estrogenic activity. On the other hand, no significant differences between the ER $\alpha$-dependent estrogenic activity of the metabolized and unmetabolized medicines were seen for any of the five examined Japanese herbal medicines (data not shown).

\section{Estrogenic activity of the crude drugs found in UKT}

In order to clarify which crude drugs were responsible for the pharmacological activity of the herbal medicines, we focused on $U K T$. As shown above, both $U K T$ and its metabolites exhibited strong estrogenic activity in both the cell proliferation bioassay and the yeast two-hybrid assay. Therefore, we investigated the estrogenic activity of the crude drugs present within $U K T$ using the cell proliferation bioassay and yeast two-hybrid assay.

In the cell proliferation bioassay, it was found that glycyrrhizae radix, cinnamomi cortex, and evodiae fructus all induced significantly greater cell proliferation than DMSO at a final concentration of $10 \mu \mathrm{g} / \mathrm{ml}(p<0.01$, Fig. 3a). Among these three crude drugs, glycyrrhizae radix also induced significantly greater proliferative activity than DMSO at a concentration of $5 \mu \mathrm{g} / \mathrm{ml}$. We also investigated the ER $\beta$-dependent estrogenic activity of the crude drugs present within $U K T$ using the yeast two-hybrid assay. As a result, glycyrrhizae radix, cinnamomi cortex, zingiberis rhizoma, and evodiae fructus were found to exhibit significantly greater activity than DMSO at final concentrations of $0.5 \mathrm{mg} / \mathrm{ml}$ and $0.1 \mathrm{mg} /$ $\mathrm{ml}$ (Fig. 3b). The activity levels of glycyrrhizae radix and evodiae fructus remained high at a concentration of $0.5 \mathrm{mg} / \mathrm{ml}$, and glycyrrhizae radix even demonstrated strong activity at a concentration of $0.1 \mathrm{mg} / \mathrm{ml}$. None of the other crude drugs displayed significant estrogenic activity in the cell proliferation bioassay or yeast twohybrid assay. These results suggest that the strong estrogenic activity of $U K T$ can be attributed to the crude drugs it contains; i.e., glycyrrhizae radix, cinnamomi cortex, zingiberis rhizoma, and evodiae fructus, especially glycyrrhizae radix.

\section{Synergistic effects of the crude drugs during combination treatment}

As described above, glycyrrhizae radix exhibited the strongest estrogenic activity of all the crude drugs in $U K T$ and is present in all three of the Japanese herbal medicines that demonstrated estrogenic activity in the $\mathrm{MtT} / \mathrm{Se}$ cell proliferation bioassay and ER $\beta$-dependent estrogenic activity in the yeast two-hybrid assay; i.e., UKT, KSS, and NSS. In order to detect inter-crude drug synergistic effects on ER $\beta$-dependent estrogenic activity, the combined effects of $0.1 \mathrm{mg} / \mathrm{ml}$ glycyrrhizae radix and $0.1 \mathrm{mg} / \mathrm{ml}$ of one of the other crude drugs present in $U K T$ were examined, and then SQ were calculated. The $\beta$-galactosidase activity of glycyrrhizae radix, evodiae fructus, and glycyrrhizae radix+evodiae fructus are shown in Fig. 4a, and the SQ for glycyrrhizae radix+evodiae fructus was calculated according to the method described above. The activity of glycyrrhizae radix+evodiae fructus was significantly greater than the sum of the activity levels of these two crude drugs alone $(p<0.01)$, which resulted in it having an SQ of 1.91 (Fig. 4a). Furthermore, we examined the contribution of such synergistic effects to ER $\beta$-dependent estrogenic activity by combining evodiae fructus with other crude drugs. Accordingly, the $\beta$-galactosidase activity of evodiae fructus, cinnamomi cortex, and evodiae fructus+cinnamomi cortex were assessed, and we found that evodiae fructus 

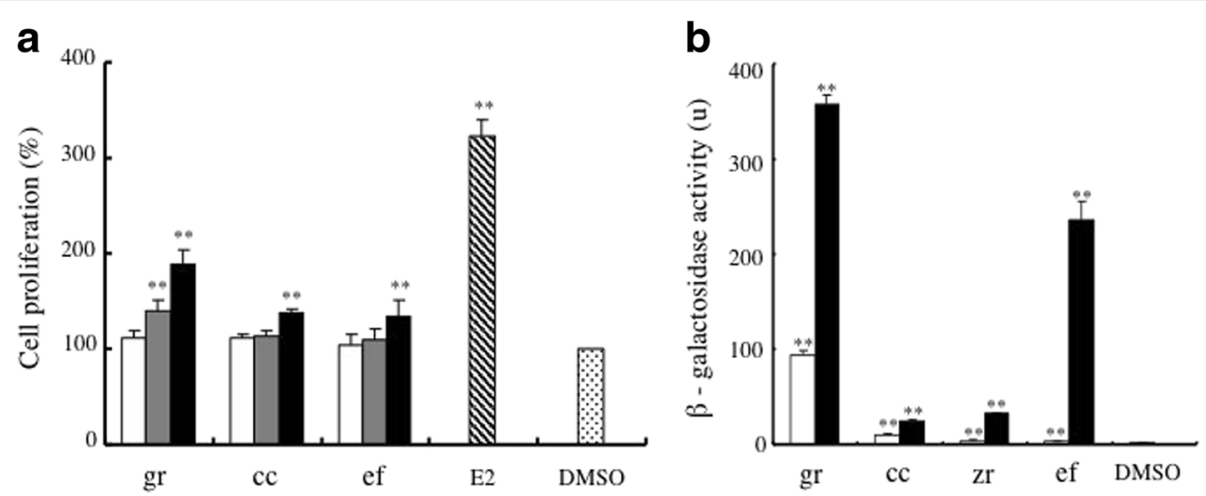

Fig. 3 The estrogenic activity of the crude drugs present in UKT. a MtT/Se cells were incubated with each of the crude drugs found in UKT at a concentration of $1 \mu \mathrm{g} / \mathrm{ml}$ (white columns), $5 \mu \mathrm{g} / \mathrm{ml}$ (gray columns), or $10 \mu \mathrm{g} / \mathrm{ml}$ (black columns), and the cell proliferation induced by treatment with these crude drugs or $10^{-7} \mathrm{M}$ of E2 for 6 days was evaluated. Cell proliferative activity is shown as a percentage compared with that induced by DMSO alone in the MTT assay. ${ }^{*}$ significantly increased compared with the activity induced by DMSO, $p<0.01$. $\mathbf{b}$ The $\beta$-galactosidase activity of all 12 of the crude drugs present in UKT was evaluated at concentrations of $0.1 \mathrm{mg} / \mathrm{ml}$ (white columns) and $0.5 \mathrm{mg} / \mathrm{ml}$ (black columns). The data for the crude drugs that did not display significant activity in the yeast two-hybrid assay are not shown. ${ }^{*}$ significantly increased compared with the activity of DMSO, $p<0.01$

+cinnamomi cortex exhibited significantly greater activity than the sum of the activity levels of evodiae fructus and cinnamomi cortex alone $(p<0.01)$. The evodiae fructus+cinnamomi cortex combination had an SQ of 2.0 (Fig. 4b). We continued examining the contribution of such synergistic effects to ER $\beta$-dependent estrogenic activity by combining cinnamomi cortex with the other crude drugs present in $U K T$. However, no other synergistic effects were found. These findings suggest that the glycyrrhizae radix+evodiae fructus and evodiae fructus +cinnamomi cortex combinations have synergistic effects on the estrogenic activity of $U K T$.

\section{Discussion}

Japanese herbal medicines are often prescribed for menopausal syndrome, which is caused by the cessation of both egg maturation and sex hormone (principally estrogen and progesterone) secretion. Therefore, we examined the pharmacological activity of Japanese herbal medicines that are used to treat menopausal syndrome, especially their estrogenic activity. In this study, the estrogenic activity of Japanese herbal medicines was evaluated using a combination of an ER-dependent cell proliferation bioassay and an ER-dependent reporter assay. ER-dependent bioassays based on $\mathrm{MtT} / \mathrm{Se}$ cells,
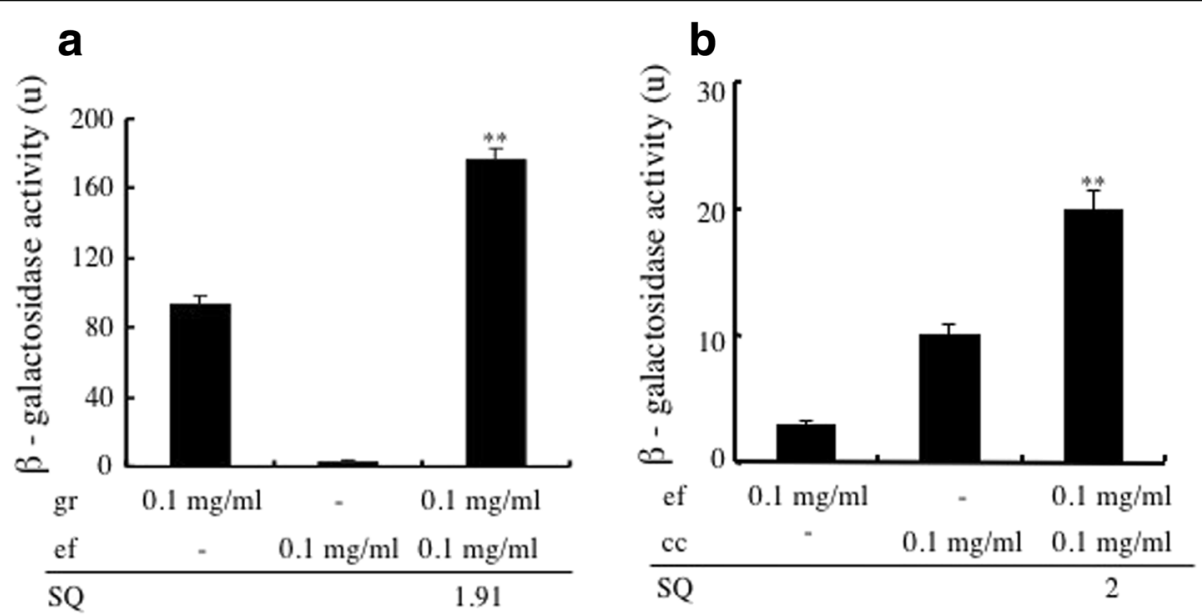

Fig. 4 Synergistic effects between the crude drugs found in UKT according to the yeast two-hybrid assay. a The synergistic effects of combining glycyrrhizae radix with other crude drugs on ERß-dependent estrogenic activity. $\mathbf{b}$ The synergistic effects of combining evodiae fructus with other crude drugs on ERß-dependent estrogenic activity. The $\beta$-galactosidase activity of the crude drugs alone and various pairs of crude drugs were evaluated at concentrations of $0.1 \mathrm{mg} / \mathrm{ml}$ (black columns). ${ }^{* *}$ significantly increased compared with the sum of the activity levels of the two crude drugs alone, $p<0.01$. SQ values were calculated to determine whether each combination had synergistic effects, as described in the materials and methods. The data for the combinations that did not have significant synergistic effects in the yeast two-hybrid assay are not shown 
which express receptors for both endogenous ER $\alpha$ and ER $\beta$ [16], can be utilized to determine the overall effects of signaling mediated by these two receptors. In order to clarify the estrogenic responses initiated by ER $\alpha$ or ER $\beta$, we used an ER-dependent yeast two-hybrid reporter assay. As described in the results, UKT, KSS, and NSS increased the proliferation of $\mathrm{MtT} / \mathrm{Se}$ cells, and this activity was markedly inhibited by ICI, an ER antagonist. These results suggest that the effects of $U K T, K S S$, and NSS on the proliferation of MtT/Se cells are directly mediated by the ER.

On the other hand, in the yeast two-hybrid assay $U K T$, KSS, and NSS exhibited ER $\beta$-dependent estrogenic activity. Furthermore, a previous study involving a luciferase assay also showed that $U K T$ and $K S S$ displayed such activity [22]. However, Watanabe et al. reported that they could not detect any agonistic activity of UKT or NSS towards hER [23], but they used aqueous solutions of herbal medicines. As E2 is soluble in fat, we extracted the herbal medicines using ethanol and prepared DMSO solutions of the medicines. Thus, the different extraction solvents used might explain the abovementioned discrepancies.

In a previous study, Pueraria mirifica, a phytoestrogenrich traditional herbal plant, bound more strongly to ER $\beta$ than ER $\alpha$ [18], and a herbal medicine composed of 18 different crude drugs displayed slightly higher affinity for ER $\beta$ [24]. UKT, KSS, and NSS are mixtures of various traditional herbal plants, and therefore, we examined whether these Japanese herbal medicines are also rich in phytoestrogens.

Phytoestrogens are naturally occurring chemicals of plant origin, which have the ability to cause estrogenic and/or antiestrogenic effects due to their structural similarity to the human hormone E2 [25]. The most common phytoestrogens can be divided into four kinds of compound, isoflavones, coumestans, prenylflavonoids, and lignans, all of which possess phenolic and hydroxyl moieties [25]. As was shown in the 3D-HPLC patterns provided by the Tsumura Corporation, isoliquiritigenin and glycycoumarin, which were detected in all three of the Japanese herbal medicines that exhibited estrogenic activity in the present study (UKT, KSS, and NSS); liquiritigenin, which was detected in UKT and KSS; and skullcapflavone II, which was only detected in NSS, also possess phenolic and hydroxyl moieties (Fig. 5). Liquiritigenin and isoliquiritigenin have been found in the licorice species Glycyrrhiza glabra, Glycyrrhiza uralensis, and Glycyrrhiza inflata [26] and licorice root extracts that displayed estrogenic activity [27]. The isoliquiritigenin found in Glycyrrhiza glabra exhibits stronger docking energy when it binds to ER $\beta$ than when it binds to ER $\alpha$ [28]. In addition, previous studies have reported that liquiritigenin demonstrated greater selective affinity for $E R \beta$ than for ER $\alpha$ [29-31]. Isoliquiritigenin is the precursor chalcone of liquiritigenin, and a previous study detected a significant reduction in isoliquiritigenin content and a corresponding increase in liquiritigenin formation in cellbased assays, which suggested that the conversion of isoliquiritigenin to liquiritigenin via cyclization might occur under physiological conditions [30]. Glycycoumarin, which was detected in UKT, KSS, and NSS, is a member of the coumarin family that exhibits estrogenic activity [32], and it has also been found to be an estrogen agonist [33]. As shown in the abovementioned 3D-HPLC analysis, the structure of glycycoumarin is similar to that of genistein, which has a linear and polar structure. ER $\beta$ has a flexible binding pocket [34], and it can accept a linear group and tolerate the resultant polarity [35]. Therefore, glycycoumarin might also have greater selective affinity for ER $\beta$. Little is known about the estrogenic activity of skullcapflavone II, which is present in NSS, but skullcapflavone II is a member of the flavone family, which is the most common type of phytoestrogen. Based on the above points, it is suggested that the estrogenic activity of UKT, KSS, and NSS is due to constituents with common phytoestrogen structures. In the present study, these Japanese herbal medicines demonstrated strong ER $\beta$-dependent estrogenic activity, but none of them displayed ER $\alpha$ estrogenic activity in the yeast two-hybrid assay.

We also investigated the estrogenic activity of Japanese herbal medicines after they had been metabolized using the rat liver S9 fraction. UKT, KSS, and NSS exhibited greater ER $\beta$-dependent estrogenic activity after they had been metabolized. Due to the very low abundance and great variety of Japanese herbal medicine metabolites, we did not identify the metabolites produced by treating the herbal medicines with the rat liver S9 fraction using 3DHPLC analysis in the current study. However, as shown in the abovementioned 3D-HPLC patterns of $U K T, K S S$, and NSS, the structures of the constituents within the oval boxes were based on a sugar or a methyl group bound to a liquiritigenin or an isoliquiritigenin. It might be possible to convert these structures into liquiritigenin or isoliquiritigenin through previously proposed metabolic pathways [36-38] (Fig. 6), and as described above liquiritigenin and isoliquiritigenin have been shown to be active estrogenic constituents. Therefore, this provides a possible explanation for the increases in the estrogenic activity of $U K T$, $K S S$, and NSS seen after they were treated with the S9 fraction. On the other hand, TSS, KBG, and their metabolites, which do not contain the most common phytoestrogen structures (data not shown), did not exhibit any estrogenic activity in the MtT/Se cell proliferation bioassay or the yeast two-hybrid assay. Thus, we consider that these two herbal medicines might exert pharmacological effects against menopausal syndrome via other mechanisms.

Herbal medicines are mixtures of several crude drugs. In order to clarify which crude drugs were responsible 

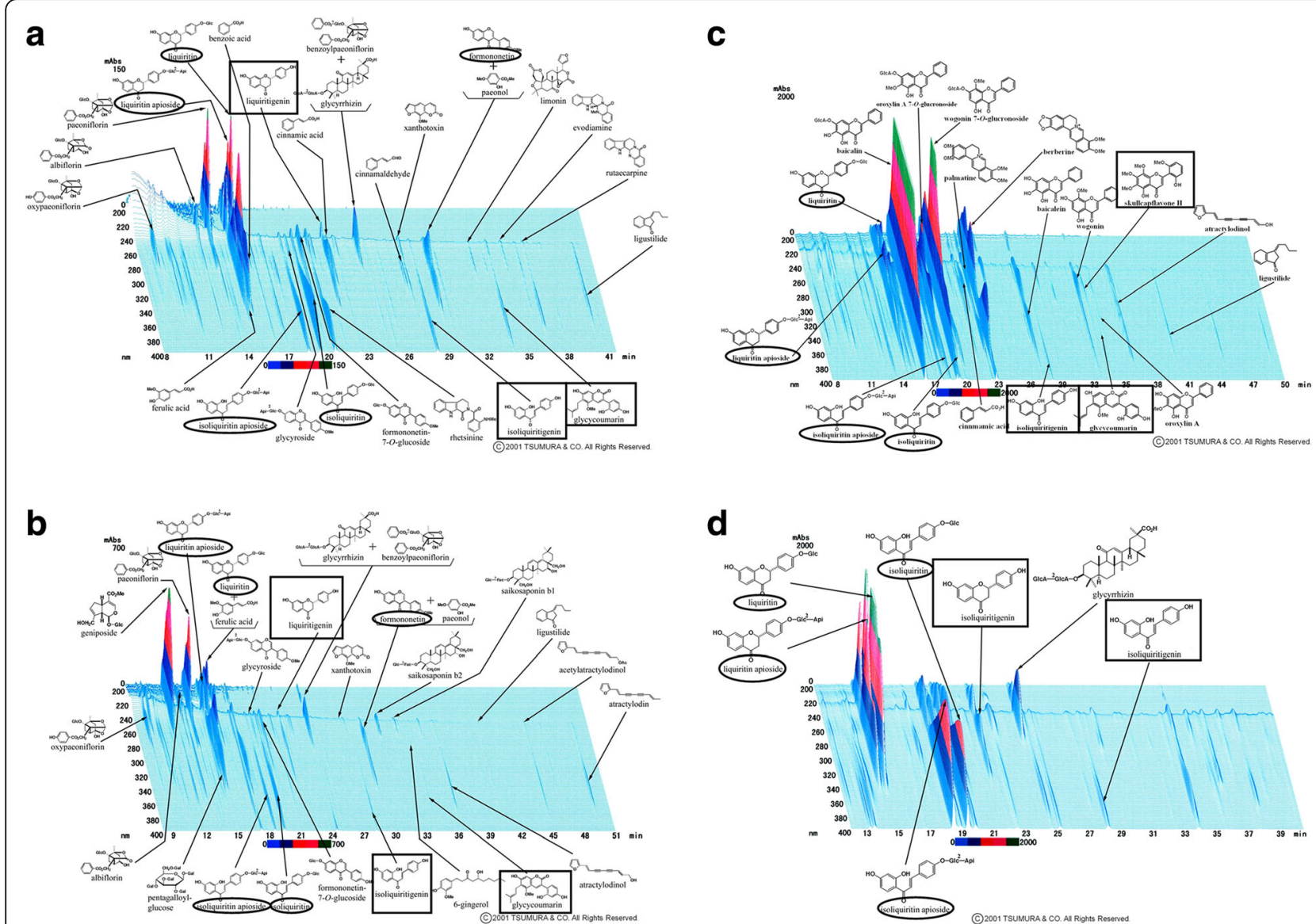

Fig. 5 3D-HPLC patterns of three Japanese herbal medicines and glycyrrhizae radix. The 3D-HPLC patterns of UKT (a), KSS (b), NSS (c), and glycyrrhizae radix (d) are shown. The constituents in the quadratic boxes possess phenolic and hydroxyl moieties, and those in the oval boxes might be convertible into active estrogenic constituents; i.e., liquiritigenin or isoliquiritigenin, through metabolic reactions

for the pharmacological activity of the examined herbal medicines, we focused on UKT and investigated the estrogenic activity of the crude drugs present within it and the synergistic effects of pairs of these crude drugs. The proportions of the crude drugs in UKT ranged from 3.7\% to 15\% (Table 1). Therefore, in this study we evaluated the estrogenic activity of the crude drugs at $10 \%$ of the tested concentrations of the Japanese herbal medicines, and glycyrrhizae radix exhibited the strongest estrogenic activity of all the crude drugs found in $U K T$.

As discussed above, UKT, KSS, NSS and their metabolites possess some constituents with common phytoestrogen<smiles>COc1ccc(C2CC(=O)c3ccc(O)cc3O2)cc1</smiles><smiles>O=C(O)c1ccc(Oc2ccc(O)cc2)cc1</smiles><smiles>O=C1CC(c2ccc(O)cc2)Oc2cc(O)ccc21</smiles>

liquiritigenin<smiles>O=C(/C=C/c1ccc(O)cc1)c1ccc(O)cc1O</smiles>

isoliquiritigenin

Fig. 6 A proposed metabolic pathway. R: a sugar group or a methyl group 
structures. We found that these constituents were mostly derived from the common crude drug glycyrrhizae radix (Fig. 5), which is a rich source of flavonoids [39, 40], and previous studies have shown that it exhibits estrogenic activity $[14,27,41]$. Furthermore, other crude drugs (cinnamomi cortex, evodiae fructus, and zingiberis rhizoma) displayed ER $\beta$-dependent estrogenic activity. It was reported that cinnamomi cortex demonstrated anti-allodynic activity [42]; evodiae fructus suppressed the proliferation of human epithelial ovarian cancer cells [43]; and zingiberis rhizoma induced nitric oxide production, which inhibited tumor cell growth [44]. As far as we know, this was the first study to examine the estrogenic activity of these crude drugs. During the analysis of the main constituents of these crude drugs, we did not detect common phytoestrogen structures; i.e., phenolic or hydroxyl moieties. A previous review examined ER $\beta$ ligands [45], and some of the ligands did have not phenolic or hydroxyl moieties. Therefore, we speculate that previously unknown phytoestrogen constituents that do not have common phytoestrogen structures, but possess affinity for ER $\beta$, are present in cinnamomi cortex, evodiae fructus, and zingiberis rhizoma. However, zingiberis rhizoma did not increase the proliferation of MtT/ Se cells in the current study.

The in vivo activity of estrogen was investigated in a previous review, which demonstrated that it involves an array of factors and is controlled by complex signaling pathways [46]. In the present study, an MtT/Se cell bioassay was used to investigate the overall effects of herbal medicines, which might also involve complex signaling pathways. Zingiberis rhizoma showed estrogenic activity, but did not have estrogenic effects on MtT/Se cells.

This study is the first to detect inter-crude drug synergistic effects on ER $\beta$-dependent estrogenic activity. Herbal medicines are made from raw plant materials, and their compositions are complex. In addition, even if the same crude drugs are present in different herbal medicines their ratios can vary. Therefore, we combined pairs of crude drugs in 1:1 ratios. This is an easy way of comparing the effects of combinations of crude drugs. We found that evodiae fructus had synergistic effects when combined with glycyrrhizae radix, and evodiae fructus also had synergistic effects when combined with cinnamomi cortex. Evodiae fructus exhibited 78-fold higher activity when its concentration was increased 5 -fold. Hence, in addition to the classical ligand-binding pattern in which one ligand binds to one $\operatorname{LBD}[34,38,47]$, we speculate that one ligand can bind to more than one LBD through a bridge-bond effect. Such mechanisms could be involved in the abovementioned synergistic effects. However, this issue needs to be clarified in future studies. In addition, several reports have shown that the unliganded ER may be transcriptionally activated by certain post-translational modifications [48]. In MCF-7 breast cancer cells, it was shown that the phosphorylation of a kinase was sufficient to allow it to directly bind to ER and activate them [49]. This mechanism might also be responsible for some synergistic effects. The combination of crude drugs can affect cell homeostasis, activate some unliganded ER, and have synergistic effects. Synergistic effects might explain why herbal medicines, which have been prescribed for thousands of years, work better than the administration of their crude drug constituents alone.

\section{Conclusions}

UKT, KSS, and NSS exhibited estrogenic activity in this study, and their activity increased further after they were metabolized. Such activity might be the key to their efficacy against menopausal syndrome. Glycyrrhizae radix is a crude drug that is found in all three of these Japanese herbal medicines, and it also displayed strong estrogenic activity. By analyzing the main constituents of these three herbal medicines, we found that some of their constituents possessed common phytoestrogen structures; i.e., phenolic and hydroxyl moieties. In addition, we demonstrated for the first time that cinnamomi cortex, evodiae fructus, and zingiberis rhizoma all display ER $\beta$-dependent estrogenic activity. The abovementioned crude drugs might contain some new phytoestrogen constituents that do not possess common phytoestrogen structures, but exhibit affinity for ER $\beta$. We also identified synergistic effects between evodiae fructus and glycyrrhizae radix, and between evodiae fructus and cinnamomi cortex for the first time. Synergistic effects between crude drugs increase the efficacy of herbal medicines. However, the mechanisms responsible for these effects remain unknown.

\section{Abbreviations \\ DMEM: Dulbecco's modified Eagle's medium; DMSO: dimethyl sulfoxide; E2: 17ß-estradiol; ER: estrogen receptor; FBS: fetal bovine serum; HPLC: high- performance liquid chromatography; HS: horse serum; LBD: ligand-binding domain; ONPG: o-nitrophenyl- $\beta-D$-galactopyranoside; SQ: synergism quotient; TIF2: transcriptional intermediary factor 2}

\section{Acknowledgments \\ We are grateful to Dr. Satoshi Takatori for providing the hERa and hER $\beta$ yeast strains. We would like to thank the Tsumura Corporation for providing the 3D- HPLC patterns of UKT (unkeito), KSS (kamishoyosan), NSS (nyoshinsan), and kanzo (glycyrrhizae radix). We thank Dr. Pheophet Lamaningao and Andrew Waleluma for their helpful technical advice and discussions throughout the experiments. We also thank Yasuko Nishimura for her kind secretarial assistance.}

\section{Funding}

Not applicable to this submission.

Availability of data and materials

All data generated or analyzed during this study are included in this published article.

\section{Authors' contributions}

SK and ZW designed this study. ZW performed all the experiments, analyzed the data, and wrote the manuscript. TS and DEU discussed the results. SK and TN supervised the entire study and assisted in the revision of the manuscript. All of the authors have read and approved the final manuscript. 


\section{Ethical approval and consent to participate}

Not applicable to this submission.

\section{Consent for publication}

Not applicable to this submission.

\section{Competing interests}

The authors declare that they have no competing interests.

\section{Publisher's Note}

Springer Nature remains neutral with regard to jurisdictional claims in published maps and institutional affiliations.

Received: 16 May 2017 Accepted: 15 March 2018

Published online: 23 March 2018

\section{References}

1. Women's NCCf. Health Cs. Menopause: Full Guideline; 2015

2. Avis NE, Stellato R, Crawford S, Bromberger J, Ganz P, Cain V, Kagawa-Singer M. Is there a menopausal syndrome? Menopausal status and symptoms across racial/ethnic groups. Soc Sci Med. 2001;52(3):345-56.

3. Organization WH. Research on the menopause in the 1990s: report of a WHO scientific. Group. 1996;

4. Xiao L, Chang AK, Zang MX, Bi H, Li S, Wang M, Xing X, Wu H. Induction of the CLOCK gene by E2-ERalpha signaling promotes the proliferation of breast cancer cells. PLoS One. 2014:9(5):e95878.

5. Han SJ, Begum K, Foulds CE, Hamilton RA, Bailey S, Malovannaya A, Chan D, Qin J, O'Malley BW. The dual estrogen receptor alpha inhibitory effects of the tissue-selective estrogen complex for endometrial and breast safety. Mol Pharmacol. 2016;89(1):14-26.

6. Chan KK, Leung TH, Chan DW, Wei N, Lau GT, Liu SS, Siu MK, Ngan HY. Targeting estrogen receptor subtypes (ERalpha and ERbeta) with selective ER modulators in ovarian cancer. J Endocrinol. 2014;221(2):325-36.

7. Lazennec G, Bresson D, Lucas A, Chauveau C, Vignon F. ER beta inhibits proliferation and invasion of breast cancer cells. Endocrinology. 2001;142(9): 4120-30.

8. Cheng J, Lee EJ, Madison LD, Lazennec G. Expression of estrogen receptor beta in prostate carcinoma cells inhibits invasion and proliferation and triggers apoptosis. FEBS Lett. 2004;566(1-3):169-72.

9. Docquier A, Garcia A, Savatier J, Boulahtouf A, Bonnet S, Bellet V, Busson M, Margeat $E$, Jalaguier $S$, Royer $C$, et al. Negative regulation of estrogen signaling by ERbeta and RIP140 in ovarian cancer cells. Mol Endocrinol. 2013;27(9):1429-41.

10. Strom A, Hartman J, Foster JS, Kietz S, Wimalasena J, Gustafsson JA. Estrogen receptor beta inhibits 17beta-estradiol-stimulated proliferation of the breast cancer cell line T47D. Proc Natl Acad Sci U S A. 2004;101(6):1566-71.

11. Hayakawa J, Noda N, Yamada S, Uno K. Studies on physical and chemical quality evaluation of crude drug preparations. I. Analysis of Pueraria Radix and species Puerariae. Yakugaku Zasshi. 1984;104(1):50-6.

12. Tamir S, Eizenberg M, Somjen D, Stern N, Shelach R, Kaye A, Vaya J. Estrogenic and antiproliferative properties of glabridin from licorice in human breast cancer cells. Cancer Res. 2000;60(20):5704-9.

13. Somjen D, Knoll E, Vaya J, Stern N, Tamir S. Estrogen-like activity of licorice root constituents: glabridin and glabrene, in vascular tissues in vitro and in vivo. J Steroid Biochem Mol Biol. 2004:91(3):147-55.

14. Simons R, Vincken JP, Mol LA, The SA, Bovee TF, Luijendijk TJ, Verbruggen MA, Gruppen H. Agonistic and antagonistic estrogens in licorice root (Glycyrrhiza glabra). Anal Bioanal Chem. 2011;401(1):305-13.

15. Inoue K, Hattori M, Sakai T, Inukai S, Fujimoto N, Ito A. Establishment of a series of pituitary clonal cell lines differing in morphology, hormone secretion, and response to estrogen. Endocrinology. 1990;126(5):2313-20.

16. Manabe M, Kanda S, Fukunaga K, Tsubura A, Nishiyama T. Evaluation of the estrogenic activities of some pesticides and their combinations using MtT/ se cell proliferation assay. Int J Hyg Environ Health. 2006:209(5):413-21.

17. Nishikawa J, Saito K, Goto J, Dakeyama F, Matsuo M, Nishihara T. New screening methods for chemicals with hormonal activities using interaction of nuclear hormone receptor with coactivator. Toxicol Appl Pharmacol. 1999:154(1):76-83.

18. Boonchird C, Mahapanichkul T, Cherdshewasart W. Differential binding with ERalpha and ERbeta of the phytoestrogen-rich plant Pueraria mirifica. Braz J Med Biol Res. 2010;43(2):195-200.
19. Takatori S, Kitagawa Y, Oda H, Miwa G, Nishikawa J, Nishihara T, Nakazawa $\mathrm{H}$, Hori S. Estrogenicity of metabolites of benzophenone derivatives examined by a yeast two-hybrid assay. J Health Sci. 2003;49(2):91-8.

20. Beebe SJ, Holloway R, Rannels SR, Corbin JD. Two classes of CAMP analogs which are selective for the two different CAMP-binding sites of type II protein kinase demonstrate synergism when added together to intact adipocytes. J Biol Chem. 1984;259(6):3539-47.

21. Wang J, Guo J, Wu S, Feng H, Sun S, Pan J, Zhang J, Beebe SJ. Synergistic effects of nanosecond pulsed electric fields combined with low concentration of gemcitabine on human oral squamous cell carcinoma in vitro. PLoS One. 2012:7(8):e43213.

22. Shiizaki K, Goto K, Ishige A, Komatsu Y. Bioassay of phytoestrogen in herbal medicine used for postmenopausal disorder using transformed MCF-7 cells. Phytother Res. 1999;13(6):498-503.

23. Watanabe K, Hyuga S, Hyuga M, Kawanish T, Hanawa T. Agonistic or antagonistic action of Kampo medicines used for menopausal symptoms on receptor estrogen subtypes ER. In: Medical and pharmaceutical society for WAKAN-YAKU. 2006;23:203-7.

24. Tiosano D, Paris F, Grimaldi M, Georgescu V, Servant N, Hochberg Z, Balaguer P, Sultan C. Evidence of ERalpha and ERbeta selectivity and partial estrogen agonism in traditional Chinese medicine. Reprod Biol Endocrinol. 2014;12:97.

25. Yildiz F: Phytoestogens in Funcitional foods. CRC Press,Taylor and Francis Group 2006.

26. Kondo K, Shiba M, Nakamura R, Morota T, Shoyama Y. Constituent properties of licorices derived from Glycyrrhiza uralensis, G. Glabra, or G. Inflata identified by genetic information. Biol Pharm Bull. 2007;30(7):1271-7.

27. Zava DT, Blen M, Duwe G. Estrogenic activity of natural and synthetic estrogens in human breast cancer cells in culture. Environ Health Perspect. 1997;105(Suppl 3):637-45.

28. Powers CN, Setzer WN. A molecular docking study of phytochemical estrogen mimics from dietary herbal supplements. In Silico Pharmacol. 2015;3:4.

29. Mersereau JE, Levy N, Staub RE, Baggett S, Zogovic T, Chow S, Ricke WA, Tagliaferri M, Cohen I, Bjeldanes LF, et al. Liquiritigenin is a plant-derived highly selective estrogen receptor beta agonist. Mol Cell Endocrinol. 2008; 283(1-2):49-57.

30. Hajirahimkhan A, Simmler C, Yuan Y, Anderson JR, Chen SN, Nikolic D, Dietz BM, Pauli GF, van Breemen RB, Bolton JL. Evaluation of estrogenic activity of licorice species in comparison with hops used in botanicals for menopausal symptoms. PLoS One. 2013;8(7):e67947.

31. Jiang $Y$, Gong $P$, Madak-Erdogan Z, Martin T, Jeyakumar M, Carlson K, Khan I, Smillie TJ, Chittiboyina AG, Rotte SC, et al. Mechanisms enforcing the estrogen receptor beta selectivity of botanical estrogens. FASEB J. 2013; 27(11):4406-18.

32. Bickoff EM, Booth AN, Lyman RL, Livingston AL, Thompson CR, Deeds $\mathrm{F}$. Coumestrol, a new estrogen isolated from forage crops. Science. 1957; 126(3280):969-70

33. Boonmuen N, Gong P, Ali Z, Chittiboyina AG, Khan I, Doerge DR, Helferich WG, Carlson KE, Martin T, Piyachaturawat $P$, et al. Licorice root components in dietary supplements are selective estrogen receptor modulators with a spectrum of estrogenic and anti-estrogenic activities. Steroids. 2015;105:42-9.

34. Shiau AK, Barstad D, Radek JT, Meyers MJ, Nettles KW, Katzenellenbogen BS, Katzenellenbogen JA, Agard DA, Greene GL. Structural characterization of a subtype-selective ligand reveals a novel mode of estrogen receptor antagonism. Nat Struct Biol. 2002;9(5):359-64.

35. Turner JV, Agatonovic-Kustrin S, Glass BD. Molecular aspects of phytoestrogen selective binding at estrogen receptors. J Pharm Sci. 2007;96(8):1879-85.

36. Yoshihara S, Mizutare T, Makishima M, Suzuki N, Fujimoto N, Igarashi K, Ohta S. Potent estrogenic metabolites of bisphenol a and bisphenol $\mathrm{B}$ formed by rat liver S9 fraction: their structures and estrogenic potency. Toxicol Sci. 2004;78(1):50-9.

37. Yan Z, Chen Y, Li T, Zhang J, Yang X. Identification of metabolites of Si-Nisan, a traditional Chinese medicine formula, in rat plasma and urine using liquid chromatography/diode array detection/triple-quadrupole spectrometry. J Chromatogr B Analyt Technol Biomed Life Sci. 2012;885-886:73-82.

38. Gruber CJ, Tschugguel W, Schneeberger C, Huber JC. Production and actions of estrogens. N Engl J Med. 2002;346(5):340-52.

39. Nomura T, Fukai T. Phenolic constituents of licorice (Glycyrrhiza species). Fortschr Chem Org Naturst. 1998;73:1-158.

40. Simons $R$, Vincken JP, Bakx EJ, Verbruggen MA, Gruppen H. A rapid screening method for prenylated flavonoids with ultra-high-performance 
liquid chromatography/electrospray ionisation mass spectrometry in licorice root extracts. Rapid Commun Mass Spectrom. 2009;23(19):3083-93.

41. Kohno H, Kouda K, Tokunaga R, Sonoda Y. Detection of estrogenic activity in herbal teas by in vitro reporter assays. Eur Food Res Technol. 2006;225(5-6): 913-20.

42. Kim C, Lee J, Kim W, Li D, Kim Y, Lee K, Kim S. The suppressive effects of Cinnamomi cortex and its Phytocompound Coumarin on Oxaliplatininduced neuropathic cold allodynia in rats. Molecules. 2016;21(10):1253.

43. Zhong Z-F, Tan W, Wang S-P, Qiang W-A, Wang Y-T. Anti-proliferative activity and cell cycle arrest induced by evodiamine on paclitaxel-sensitive and -resistant human ovarian cancer cells. Sci Rep. 2015;5(1):16415.

44. Liao H. Effects of Shengjiang (Zingiberis Rhizoma Recens) and its processed products on nitric oxide production in macrophage RAW 264.7 cells. Evid Based Complement Alternat Med. 2015;2015:1-5.

45. Minutolo F, Macchia M, Katzenellenbogen BS, Katzenellenbogen JA. Estrogen receptor beta ligands: recent advances and biomedical applications. Med Res Rev. 2011:31(3):364-442.

46. Zhao C, Dahlman-Wright K, Gustafsson JA. Estrogen signaling via estrogen receptor \{beta\}. J Biol Chem. 2010;285(51):39575-9.

47. Matthews J, Gustafsson JA. Estrogen signaling: a subtle balance between ER alpha and ER beta. Mol Interv. 2003;3(5):281-92.

48. Maggi A. Liganded and unliganded activation of estrogen receptor and hormone replacement therapies. Biochim Biophys Acta (BBA) - Mol Basis Dis. 2011;1812(8):1054-60.

49. Carascossa S, Dudek P, Cenni B, Briand PA, Picard D. CARM1 mediates the ligand-independent and tamoxifen-resistant activation of the estrogen receptor by CAMP. Genes Dev. 2010;24(7):708-19.

\section{Submit your next manuscript to BioMed Central} and we will help you at every step:

- We accept pre-submission inquiries

- Our selector tool helps you to find the most relevant journal

- We provide round the clock customer support

- Convenient online submission

- Thorough peer review

- Inclusion in PubMed and all major indexing services

- Maximum visibility for your research

Submit your manuscript at www.biomedcentral.com/submit 